\title{
Trends in Childbearing and Nuptiality in Sweden: An Update with Data up to 2007
}

\author{
GUNNAR ANDERSSON, Ph.D., Professor \\ MARTIN KOLK, Ph.D. Student \\ Stockholm University Demography Unit, Sweden
}

\begin{abstract}
We present an update of the main features of recent trends in vital family-demographic behavior in Sweden. For this purpose, time series of relative risks of childbearing, marriage, and divorce by calendar year are updated with another five years of observation added to previously published series. We demonstrate that fertility in Sweden continued its upward trend during much of the first decade of the 21 st century. The rise pertains to all birth orders. It is driven by the halt in postponement of first childbearing at the younger ages and the continued fertility recuperation at higher ages. Marriage propensities increased as well, reversing a decades-long trend of decreasing marriage rates. The trend reversal comprises first marriages and remarriages alike. Interestingly, the increased popularity of marriage and childbearing is accompanied with a slight decline in divorce risks during the first decade of the new century.
\end{abstract}

Keywords: fertility, marriage, divorce, period trends, Sweden

\section{Our update}

We provide an update of previous presentations of trends in family-demographic behavior of women in Sweden (Andersson and Liu 2001, Andersson 2004a), covering childbearing and nuptiality developments up to 2007 . These trends are presented in the form of a number of calendar-year series of childbearing, marriage, and divorce risks (Figures 1-8). Our calculations are based on data derived from Swedish population registers, made available to us by Statistics Sweden and maintained in a database called STAR (Sweden over Time: Activities and Relations). We have access to longitudinal information on all births and civil-status changes in Sweden of all registered resident women and men in that country. Our childbearing analyses are based on women born in Sweden since 1925, with a presentation of childbearing trends in 1961-2007. Divorce registers were not reliable before 1968; therefore we restricted our study on civil-status changes to 1971 and onwards. It is based on women born in Sweden after 1945. 
Following a method suggested by Hoem (1991a, 1993) we provide family-demographic trends by using time series of indexes on the propensity of a woman to form a marriage, to divorce, or to give birth during a specific calendar year. The indexes are relative risks of childbearing, marriage formation and divorce in a given calendar year relative to a suitable baseline year. For example, a divorce risk of 1.25 for a certain year means that the propensity to divorce was 25 percent higher in that year than in the selected baseline year $^{1}$. In our calculations, we standardize for the effects of a number of demographic background variables, which means that we control for the effect of compositional changes among women over the categories of these variables. We standardize for suitable representations of age, parity, premarital childbearing, and the durations since marriage formation, divorce, and any last previous birth; see the subheadings of Figures 1-8. We focus explicitly on the effect the number of previous live births has on demographic behavior by presenting separate time series of relative risks for women at different parities. For a thorough description of our system of period analysis, see Andersson (2001). Additional information on specific aspects of Swedish divorce dynamics can be obtained from Andersson (1997); related information on patterns in marriage formation are provided by Andersson (1998) and Ohlsson-Wijk (2011a); related information on childbearing dynamics are available in Andersson (1999).

\section{Increasing fertility in Sweden: halt in fertility postponement at younger ages, continued fertility recuperation at higher ages}

During the last half of a century, childbearing trends in Sweden have been highly volatile (Hoem and Hoem 1996; Andersson 1999; for a comparison with neighboring Denmark and Norway, see Andersson 2004b). First-birth fertility of younger women declined continuously from the mid-1960s to the mid-80s; from the early 80 s it rose markedly for women in their 30s and 40s, altogether reflecting a general postponement of entry into motherhood (Figure 1, see also Billari et al. 2007). During the 1980s, birth propensities increased for mothers at different parities as well (Figures 2-3). The 1990s, by contrast, were characterized by strong declines in birth risks. As in the 1980s, this trend was followed by women at all parities. In general, these trends have evolved in tandem with the business cycle (Hoem 2000; Andersson 2000). We observe another uniform trend reversal towards the end of the 1990s: Birth propensities of mothers (Figures 2-3) and childless women aged 31 and above (Figure 1) experienced renewed increases after 1997. The rises continued without interruption during the whole tenyear period through 2007. For younger childless women (Figure 1), a new trend can be observed as well, as birth propensities have remained stable during all years since 1998. Evidently, fertility postponement at the younger ages has made a halt, which together with the continued recuperation in first childbearing at the higher ages and

1 The choice of baseline year is arbitrary: a change of baseline merely leads to the proportional re-scaling of the risks for other calendar years. 
the increased childbearing propensities of mothers tended to push aggregate fertility measures upwards. The TFR of Sweden in 2007 was 1.88 .

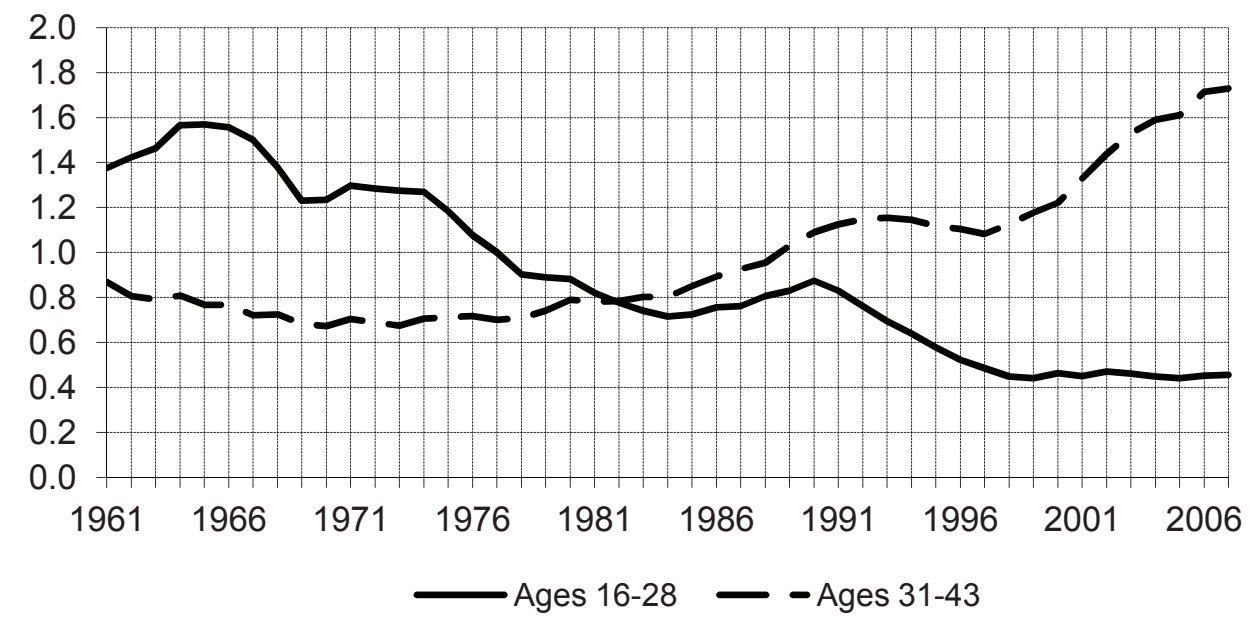

Figure 1. Relative risk of first childbearing, by calendar year and age group. Swedish childless women, 1961-2007, standardized for age in single years. Rates relative to rates of younger women in 1977.

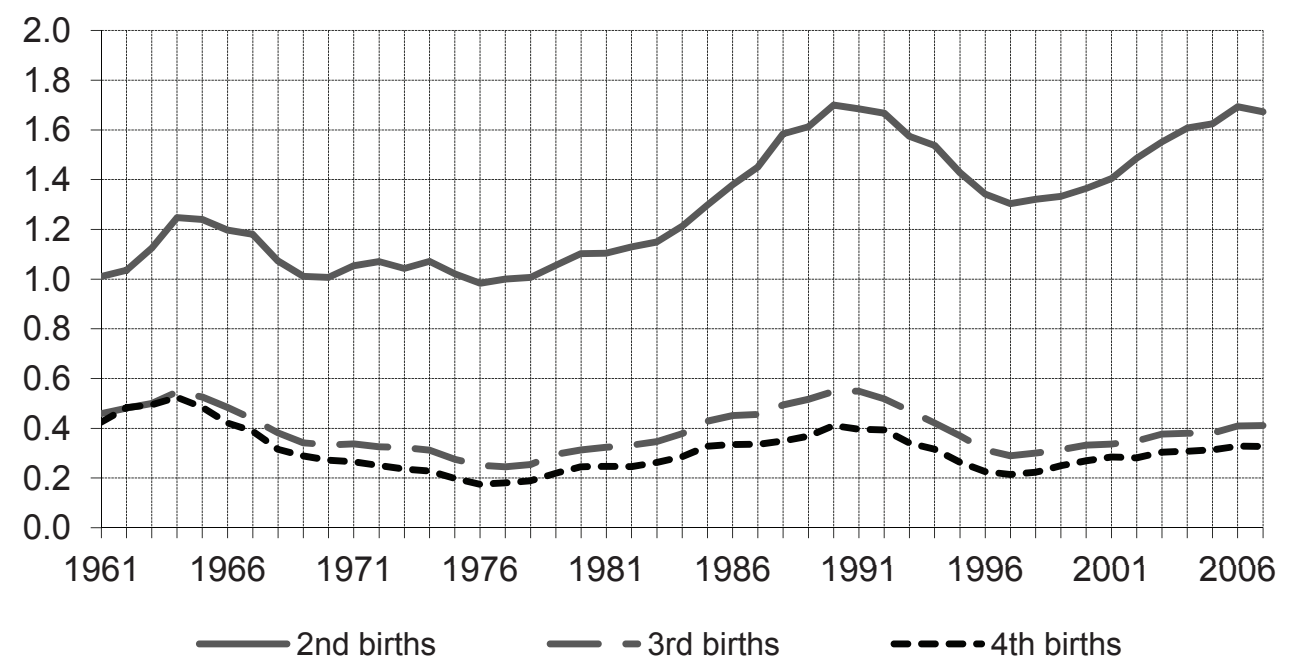

Figure 2. Relative risk of second, third and fourth birth, by calendar year. Swedish mothers, 1961-2007, standardized for age of mother and duration since previous birth. Rates relative to second-birth rates in 1977. 


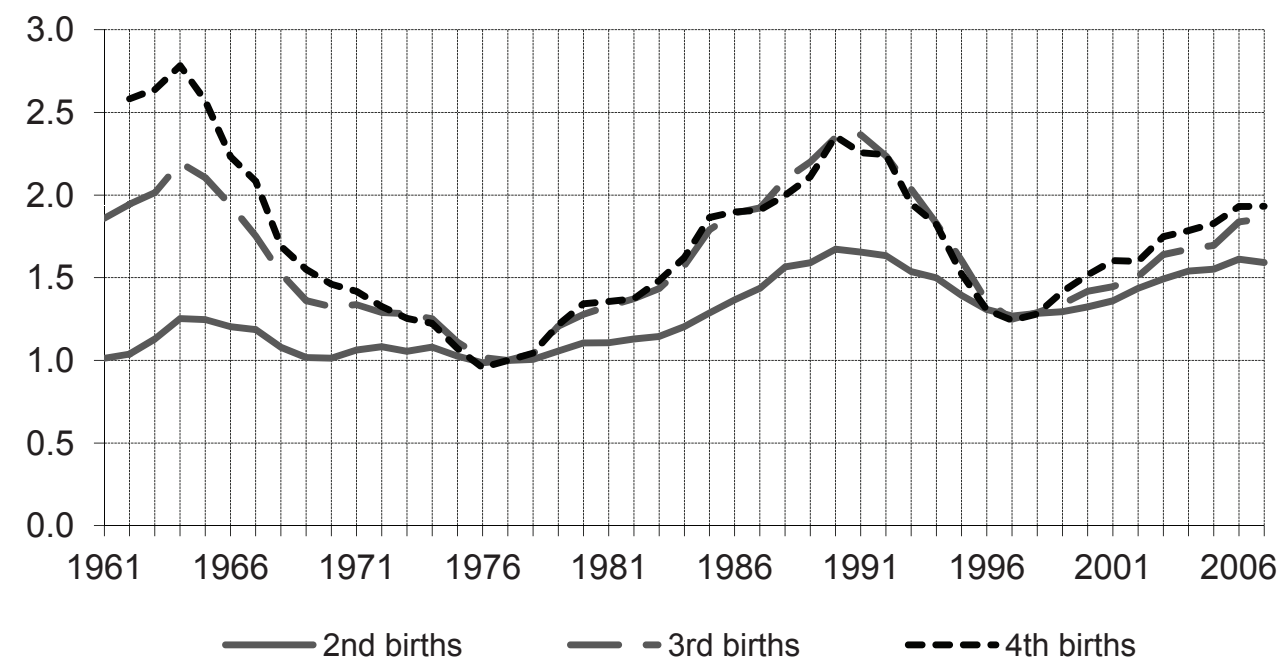

Figure 3. Relative risk of second, third and fourth birth, by calendar year. Swedish mothers, 1961-2007, standardized for age of mother and duration since previous birth. Rates relative to rates in 1977 for each birth order (separate models for each order).

\section{Trend reversal in marriage formation in Sweden}

During the 1970 s, the propensity to marry decreased dramatically and continued to decline during the subsequent two decades, although at a much more moderate pace (Andersson 1998). In sharp contrast to this long-term trend, a spectacular but temporary rise in marriage propensities occurred in 1989 in response to the introduction of new rules concerning eligibility for a widow's pension (see Hoem 1991b for a discussion). Starting in 1999, we find a subsequent trend reversal in marriage-formation propensities. The turn of the millennium appears to have triggered an additional number of people to marry in 2000, perhaps due to some digital preferences of people (Ohlsson-Wijk 2011b). In each of the years from 2002 to 2007 marriage rates increased (Figure 4). Marriage propensities increased for never-married women at all parities, but much more strongly for mothers than for childless women (Figure 5). Re-marriage propensities increased as well (Figure 6). For further information and analysis of these new trends, see Ohlsson-Wijk (2011a). 


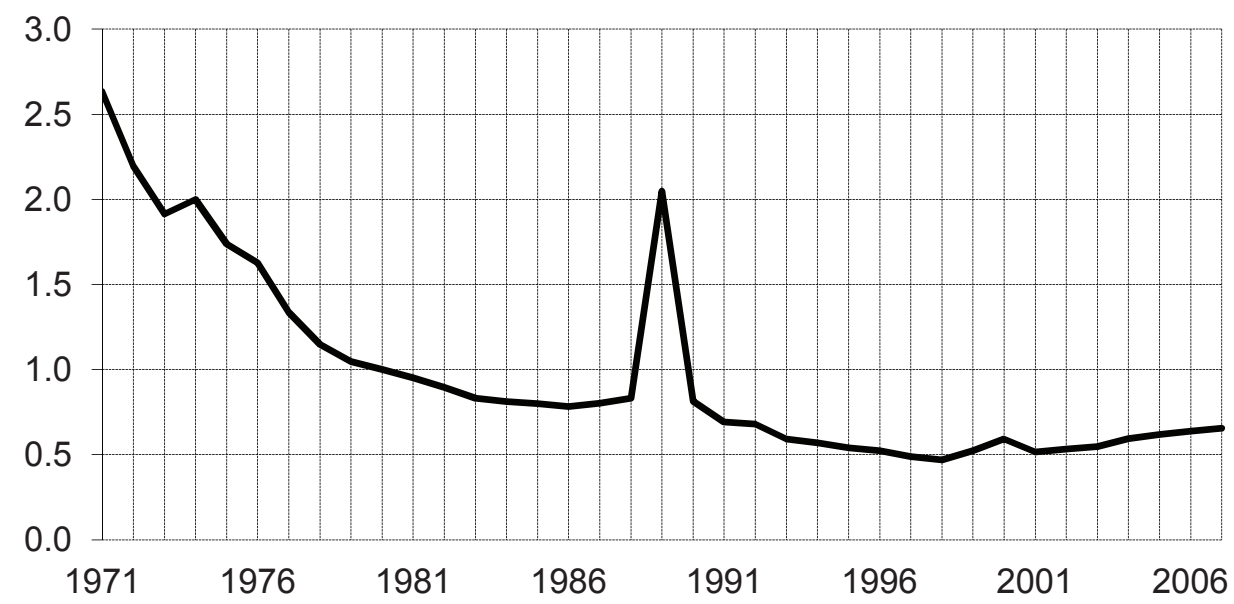

Figure 4. Relative risk of marriage formation, by calendar year. Never-married Swedish women, 1971-2007, standardized for parity and age. Rates relative to rates in 1980.

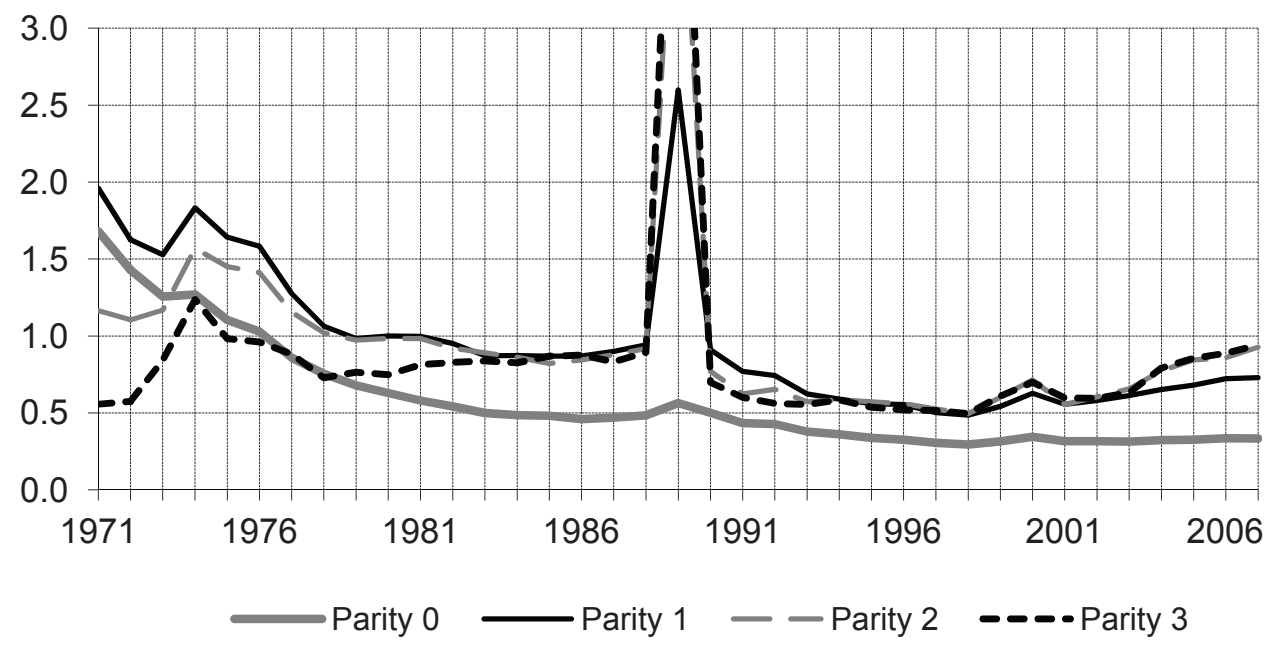

Figure 5. Relative risk of marriage formation, by parity and calendar year. Nevermarried Swedish women, 1971-2007, standardized for age. Rates relative to rates of one-child mothers in 1980. 


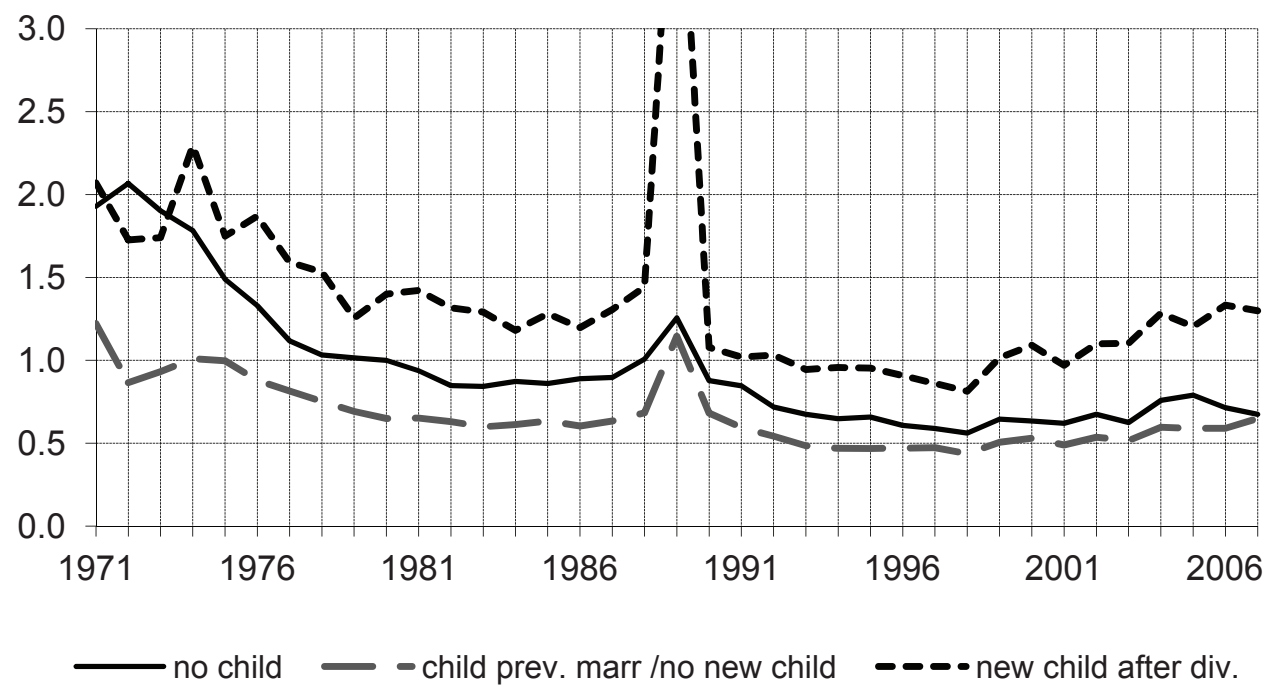

Figure 6. Relative risk of re-marriage, by parity and calendar year. First-divorced Swedish women, 1971-2007, standardized for age and time since divorce. Rates relative to rates of childless women in 1980 .

\section{Trend reversal in Swedish divorce risks}

The divorce risk rose sharply in 1974 in response to the liberalization of divorce legislation in that year. From the 1980 s to the end of the $20^{\text {th }}$ century, standardized divorce risks increased again but this time more gradually (Andersson 1997). To a large extent, the rise in 1974 was due to a growing propensity for divorce among childless women, the later increase can be attributed to a rise in divorce risks among mothers, who constitute the vast majority of married women. Interestingly, our update reveals a recent trend reversal in divorce risks as well. The propensity to divorce leveled off during the first years of the new century. For the years covered by our update we even note a slight decline in divorce risks (Figure 7). This trend reversal is mainly due to declining divorce risks among mothers (Figure 8). Seen together with the recent trend reversals in marriage formation and childbearing we may need to start posing new questions about the underlying dynamics behind the recent family developments in Sweden. 


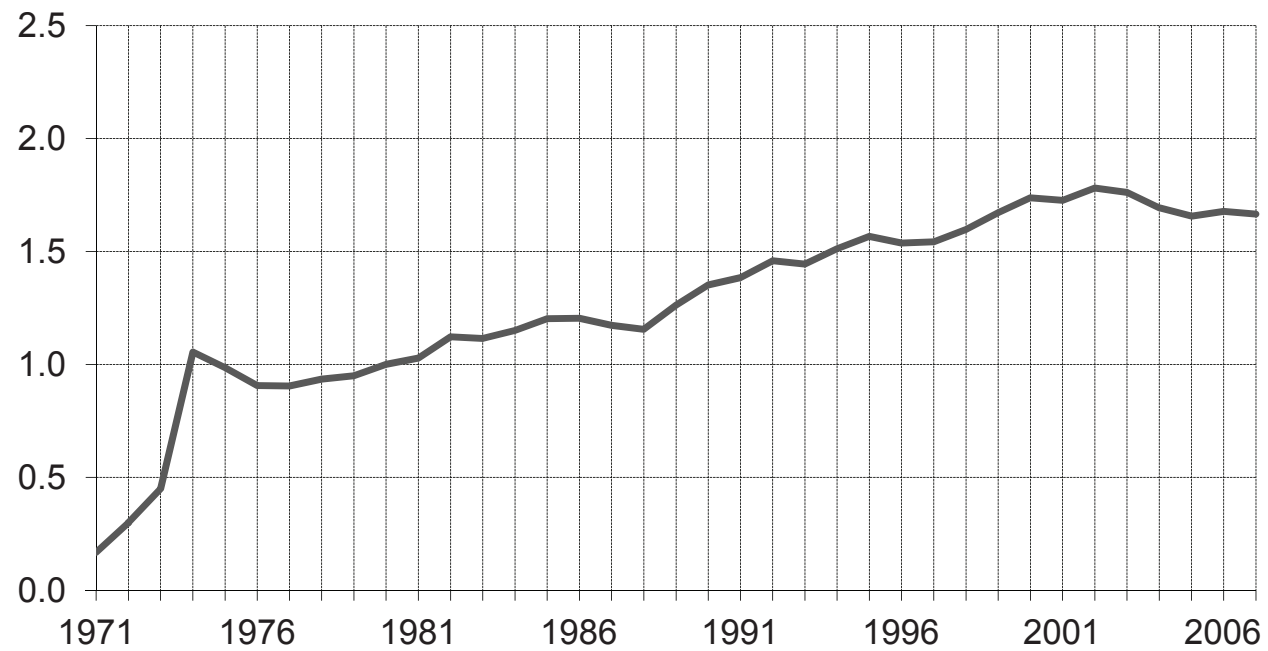

Figure 7. Relative risk of divorce, by calendar year. First-married Swedish women, 1971-2007, standardized for age, parity, premarital childbearing, duration since previous birth, and duration of marriage. Rates relative to rates in 1980.

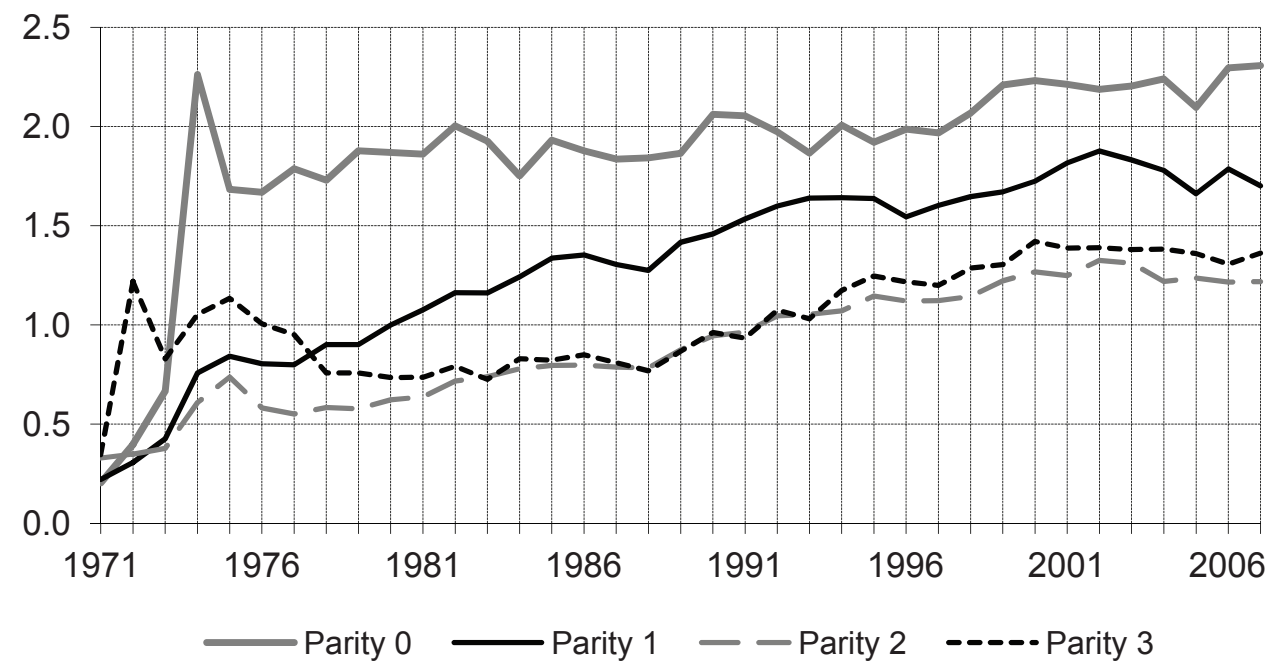

Figure 8. Relative risk of divorce, by parity and calendar year. First-married Swedish women, 1971-2007, standardized for age and duration of marriage. Risks for mothers also standardized for duration since previous birth and premarital childbearing. Rates relative to rates for one-child mothers in 1980 . 


\section{Summary}

In this presentation, we provided an update of previously published time series of relative risks of childbearing, marriage formation and divorce in Sweden, adding years 2003-2007 to the picture. Our update reveals some distinct trend reversals in recent family demographic behavior: since around the turn of the century relative risks of marriage formation and childbearing are increasing while divorce risks are decreasing. These developments challenge common stereotypes of Sweden as an eternal forerunner in the erosion of the family and pose new questions on the nature of the family demographic trends that may appear in a society at an advanced stage of the Second Demographic Transition (see, e.g., Leasthaeghe 2010). Evidently, more research is needed to understand the nature of the recent "familistic" family trends of Sweden.

\section{Acknowledgements}

We are grateful for financial support from the Swedish Research Council, Vetenskapsrådet, via the Swedish Initiative for research on Microdata in the Social and Medical Sciences, SIMSAM.

\section{References}

Andersson, Gunnar, 1997. The impact of children on divorce risks of Swedish women. European Journal of Population 13(2): 109-145.

Andersson, Gunnar, 1998. Trends in marriage formation in Sweden 1971-1993. European Journal of Population 14(2): 157-178.

Andersson, Gunnar, 1999. Childbearing trends in Sweden 1961-1997. European Journal of Population 15(1): 1-24.

Andersson, Gunnar, 2000. The impact of labour-force participation on childbearing behavior: Pro-cyclical fertility in Sweden during the 1980s and the 1990s. European Journal of Population 16(4): 293-333.

Andersson, Gunnar, 2001. Trends in childbearing and nuptiality in Sweden, 1961(71)1997. In: Tedebrand, L.-G., Sköld, P. (Eds.): Nordic Demography in History and Present-day Society. Umeå, Sweden: Umeå University, 67-100.

Andersson, Gunnar, 2004a. Demographic trends in Sweden: An update of childbearing and nuptiality up to 2002. Demographic Research 11(4): 95-110. Available from: http://www.demographic-research.org/Volumes/Vol11/4/11-4.pdf

Andersson, Gunnar, 2004b. Childbearing developments in Denmark, Norway, and Sweden from the 1970s to the 1990s: A comparison. Demographic Research Special Collection 3(7): 155-176. Available from: http://www.demographic-research.org/ special/3/7/s3-7.pdf

Andersson, Gunnar, and Liu Guiping, 2001. Demographic trends in Sweden: Childbearing developments in 1961-1999, marriage and divorce developments in 1971-1999. Demographic Research 5: 65-78. Updated as: Demographic trends in Sweden: Childbearing developments in 1961-2000, marriage and divorce 
developments in 1971-1999. Demographic Research 5: A1-A14.

Billari, Francesco, Hans-Peter Kohler, Gunnar Andersson, and Hans Lundström, 2007. Approaching the limit: Long-term trends in late and very late fertility. Population and Development Review 33(1): 149-170.

Hoem, Britta, 2000. Entry into motherhood in Sweden: The influence of economic factors on the rise and fall in fertility, 1986-1997. Demographic Research [Online] 2(4). Available from: http://www.demographic-research.org/volumes/vol2/4/2-4.pdf

Hoem, Britta, and Jan M. Hoem, 1996. Sweden's family policies and roller-coaster fertility. Jinko Mondai Kenkyu (Journal of Population Problems) 52: 1-22.

Hoem, Jan M., 1991a. La standardisation indirecte améliorée et son application à la divortialité en Suède (1971-1989). Population 46(6): 1551-1568.

Hoem, Jan M., 1991b. To marry, just in case ...: the Swedish widow's-pension reform and the peak in marriages in December 1989. Acta Sociologica 34(2): 127-135.

Hoem, Jan M., 1993. Classical demographic methods of analysis and modern eventhistory techniques. IUSSP: 22nd International Population Conference, Montreal, Canada, Volume 3: 281-291.

Lesthaeghe, Ron, 2010. The unfolding story of the Second Demographic Transition. Population and Development Review 36(2): 211-251.

Ohlsson-Wijk, Sofi, 2011a. Sweden's marriage revival: An analysis of the newmillennium switch from long-term decline to increasing popularity. Population Studies 65(2): 183-200.

Ohlsson-Wijk, Sofi, 2011b. Millennium marriages and birthday peaks in Sweden: Increased marriage propensities around specific dates. Stockholm Research Reports in Demography 2011:13. Stockholm University Demography Unit 